\title{
ERRATUM
}

\author{
A. Barel $\cdot$ M. Calomme $\cdot$ A. Timchenko \\ K. De Paepe $\cdot$ N. Demeester $\cdot$ V. Rogiers \\ P. Clarys $\cdot$ D. Vanden Berghe
}

\section{Effect of oral intake of choline-stabilized orthosilicic acid on skin, nails and hair in women with photodamaged skin}

Published online: 10 January 2006

(C) Springer-Verlag 2006

\section{Arch Dermatol Res (2005) 297:147-153}

In the original publication the name of the author K. De Paepe was rendered incorrectly.

The online version of the original article can be found at http:// dx.xoi.org/10.1007/s00403-005-0584-6

\footnotetext{
A. Barel $\cdot$ A. Timchenko $\cdot$ P. Clarys

Faculty of Physical Education and Physiotherapy,

Vrije Universiteit Brussel, Brussels, Belgium
}

M. Calomme $(\bowtie) \cdot$ N. Demeester · V. Rogiers · D. Vanden Berghe Department of Pharmeceutical Sciences Faculty of Pharmaceutical, Biomedical and Veterinary Sciences, University of Antwerp, Universiteitsplein 1, 2610 Wilrijk-Antwerp, Belgium

E-mail: microfar@ua.ac.be

Tel.: + 32-3-8202550

Fax: + 32-3-8202544

K. De Paepe

Faculty of Medicine and Pharmacy, Vrije Universiteit Brussel, Brussels, Belgium 